\title{
PREDICTING TIMING AND LOCATION OF RAINFALL TRIGGERING SHALLOW LANDSLIDES
}

\author{
Raj Hari SHARMA ${ }^{1}$ and Hajime NAKAGAWA ${ }^{2}$ \\ ${ }^{1}$ Student Member of JSCE, Graduate Student., Graduate School of Civil Engineering and Earth Resources, Kyoto \\ University (Yoshida-Honmach, Sakyo-ku, Kyoto 606-8501, Japan) \\ ${ }^{2}$ Member of JSCE, Dr. of Eng., Professor, Disaster Prevention Research Institute, Kyoto University (Shimomisu, \\ Yoko-oji, Fushimi-ku, Kyoto 612-8235, Japan)
}

\begin{abstract}
For an assessment of how hydrologic processes influence the location and timing of landslide or to assess how landslide risk might change in response to changed landuse pattern, some sort of mathematical model is needed, which can incorporate all triggering factors explicitly. Proposed landslide model explicitly analyzes the effect of high-intensity and short-duration rainfalls on development of pore-water pressure. Richards equation is used to evaluate the pore-water pressure response to the changing rainfall pattern and attendant change in Safety Factor of the stability of a location. The numerical solution of the unsteady pore-water pressure is experimentally verified in lab. The model is able to predict the timing and location of the shallow landslides. It is used to simulate the landslides occurred in 1973/10/26 at the Takora basin located upstream of Kizu river basin. The result of model encourages for development of more generalized model in future incorporating more factors that influence landslide.
\end{abstract}

Keywords: Shallow Landslide, Rainfall, prediction, hydrology, slope stability

\section{INTRODUCTION}

Increasing demands on land due to population pressure, is leading to expansion of development on landslide susceptive area also. This raises the risk of human casualties and loss of property. Hence, analysis and forecast of spatial and temporal distribution of shallow landslide becomes urgent necessity for land management in mountainous area in order to reduce risk to human population and development.

In general, approaches of available landslide prediction, can be categorized in three different groups: 1) empirical analysis of landslide, which establishes the threshold rainfall to forecast timing of landslide and is totally based on historical records; 2) empirical mapping of landslide locations, which uses past landslide events, and assume the same conditions still holds, assign a given degree of danger to all hillslope elements that feature analogous conditions; and 3) mechanistic modeling of hydrology and slope stability, which uses landslide triggering factors in an explicit way ${ }^{1)}$.

The mechanistic model of shallow landslide hazard is made after coupling simple mechanistic slope stability model and hillslope hydrological model. This type of model can explicitly take account the non-homogeneity of soil, topography and wavering rainfall. This approach can be applied to new catchments also where previous histories of landslides were not recorded.

Modeling change in pore water pressure due to rainfall is one important part of mechanistic landslide modeling. Most of the "wetting front advancing infiltration model" uscd in the shallow landslide prediction is gravity plug movement of the moisture ${ }^{.2)}$ but the real scenario provokes differently. In reality the wetting front have variable moisture distribution throughout and is highly dependent on the soil characteristics and the rainfall intensity.

The thickness of soil mantle, i.e. the failure depth, is another critical parameter in mechanistic modeling. Even in the top soil mantle the permeability of the soil is different throughout the depth. Presence of highly permeable upper layer above the less permeable layer can be seen in most of the watersheds. Incorporation of organic matter and the activity of roots results a relatively high permeable layer in the surface soil horizons. Layers with lower conductivity may originate in 


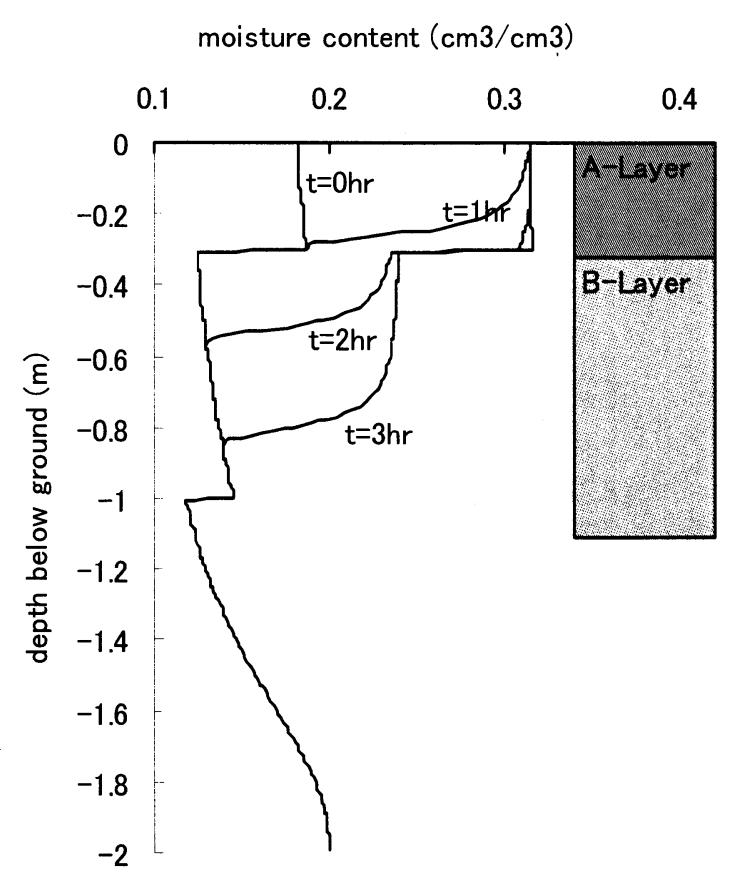

Fig.1 Conceptual representation of three-layered soil column and the change in moisture distribution in vertical direction in different time steps using $R E$

subsurface horizons from clay enrichment, cemented soil horizons, compacted layers, or consolidated bedrock. The formation of a soil crust on cultivated bare soils, resulting from the direct impact of raindrops on the surface, is also known to produce the layering effect ${ }^{3}$.

In this work we prepare a landslide prediction model that can simulate transient pore-pressure change in layered soil and corresponding slope failure. Transient unsaturated-saturated flow and its corresponding change in pore water pressure is computed using Richards equation (RE). Combination of Darcy's/Buckingham's law as applied to unsaturated flow and the equation of continuity, referred as the Richards equation, is probably considered the best method available for computing unsteady, variable saturated groundwater flow. The model calculates the pore pressure uniquely from the build up of a saturated layer above predefined critical slip surface. We use RE so that negative/positive pore pressure can be included in the infinite slope stability model. The soil domain is assumed to consist of three layers with different soil properties.

\section{HYDROLOGIC MODELING}

Hydrology plays a significant role on the shallow landslide modeling. More precisely the moisture distribution on the soil can be assessed; more exactly the location and the timing of the landslide can be estimated. This model takes account the slope parallel and slope normal redistribution of the pore water pressure associated with the transient infiltration of the rain.

Soil moisture movement is highly dependent on the layering characteristic of the soil mantle (Fig.1). The most usual case is that, the upper layers are more permeable than the lower layers. In general, saturated hydraulic conductivity of the top $30 \mathrm{~cm}$ is around $72 \mathrm{~mm} / \mathrm{hr}, 30 \mathrm{~cm}-100 \mathrm{~cm}$ is around $36 \mathrm{~mm} / \mathrm{hr}$ and the layer below $1 \mathrm{~m}$ has less then $4 \mathrm{~mm} / \mathrm{hr}^{2}$. Hence, there will be surface runoff created if the rainfall is more than saturated hydraulic conductivity of the top layer and the water table in each layer will be created if the infiltration rate of the upper layer is larger than saturated hydraulic conductivity of the immediate lower layer. Lateral flow occurs under gravitational force parallel to the slope of the land, if surface water or water table within the soil layers exists.

To evaluate the change in pore water pressure, pressure based RE given as in Eq.(1) is used because pressure profile exhibits fairly uniform shape but there may be strong discontinuity of the moisture content profile at the interference of the two layers ${ }^{3)}$. Fig.1 also supports the arguments showing sharp discontinuity of moisture content profile at the interface of the layers.

$$
\begin{aligned}
& C \frac{\partial h}{\partial t}=\frac{\partial}{\partial x}\left\{K_{x}(h)\left(\frac{\partial h}{\partial x}-\sin \alpha\right)\right\} \\
& +\frac{\partial}{\partial y}\left\{K_{y}(h) \frac{\partial h}{\partial y}\right\}+\frac{\partial}{\partial z}\left\{K_{z}(h)\left(\frac{\partial h}{\partial z}-\cos \alpha\right)\right\}
\end{aligned}
$$

where, $h$ is pressure head, $C$ is rate of change in moisture content per unit change in pressure head $(\partial \theta / \partial h), \theta$ is soil volumetric water content, $\mathrm{t}$ is time, $\alpha$ is slope angle, $K_{x}(h), K_{y}(h)$ and $K_{z}(h)$ are hydraulic conductivity in $x \quad y$ and $z$ directions (Fig.2), respectively. The hydraulic conductivities may vary owing to variations of $h$ at the unsaturated state, at saturation they becomes saturated hydraulic conductivity $K_{s}$

In order to solve $\mathrm{RE}$, the constitutive equations which relate the pressure head to the moisture content and the relative hydraulic conductivity are required. In this study, following constitutive relationships (Eq.(2), Eq.(3) and Eq.(4)) proposed by van Genuchten are used for establishing relationship of $K-h$ and $\theta-h$, with $m=1-(1 / n)$.

$$
\begin{aligned}
& K=\left\{\begin{array}{ccc}
K_{s} S_{e}{ }^{0.5}\left[1-\left(1-S_{e}{ }^{1 / m}\right)^{m}\right. & \text { for } & h<0 \\
K_{s} & \text { for } & h \geq 0
\end{array}\right. \\
& S_{e}=\left\{\begin{array}{cc}
\left(1+|\beta h|^{n}\right)^{-m} & \text { for } h<0 \\
1 & \text { for } h \geq 0
\end{array}\right.
\end{aligned}
$$




$$
S_{e}=\frac{\theta-\theta_{r}}{\theta_{s}-\theta_{r}}
$$

where, $K_{s}$ is the saturated hydraulic conductivity, $\beta$ and $n$ are parameters related with matric potential of soil and are measure of capillary fringe thickness and pore size distribution of soil respectively., $S_{e}$ is the effective saturation $\theta_{s}$ and $\theta_{r}$ are saturated and residual moisture content respectively.

\section{SLOPE STABILITY MODELING}

An infinite slope model has been widely used to compute Safety Factor (SF) provided the length of failure is larger (more than 10times) than the failure depth. This model assumes, therefore, that the resistances to movement along the sides and ends of the landslide are not significant. In this theory downslope component of the weight of the soil domain just at failure, is equal to the strength of resistance caused by cohesion (soil cohesion and/or root strength), and by frictional resistance due to the effective normal stress on the failure plane.

In this study we use a three-layer soil model (Fig.1). A-layer influenced by the vegetation has high permeability. B-layer is composed of the deposited materials that were dissolved in A-layer. $\mathrm{C}$-layer is composed of weathering rocks on the fresh bedrocks. It is assumed that slope failures caused by heavy rainfalls can occur only on the bottom of A-layer or B-layer. Slip surface is regarded as parallel to the slope. We also assume uniform soil properties throughout the basin since such spatially variable data are generally unavailable in ungauged basins.

$\mathrm{SF}$ is calculated as a ratio of the resisting and driving shear stress developed at interface of two layers. The acting shear stress, $\tau_{A}$ and the resistance shear stress, $\tau_{A L}$, at the interface of A/B-layer, are expressed respectively by

$$
\begin{aligned}
& \tau_{A}=g \sin \alpha \cos \alpha\left[\rho\left\{\begin{array}{l}
D_{A}\left(1-\lambda_{A}\right) \sigma_{A}+ \\
\left.D_{A} \int_{A}^{-H_{A}} \theta d z+H_{A} \lambda_{A}+H_{s}\right\}
\end{array}\right]\right. \\
& \tau_{A L}=g \cos ^{2} \alpha\left[\begin{array}{l}
\left(D_{A}-H_{A}\right)\left(1-\lambda_{A}\right) \sigma_{A} \\
+\rho \int_{0}^{D_{A}-H_{A}} \theta d z \\
+H_{A}\left(1-\lambda_{A}\right)\left(\sigma_{A}-\rho\right) \\
+\rho H_{s}
\end{array}\right] \tan \phi_{A}+c_{A}
\end{aligned}
$$

In the same manner the acting shear stress, $\tau_{B}$
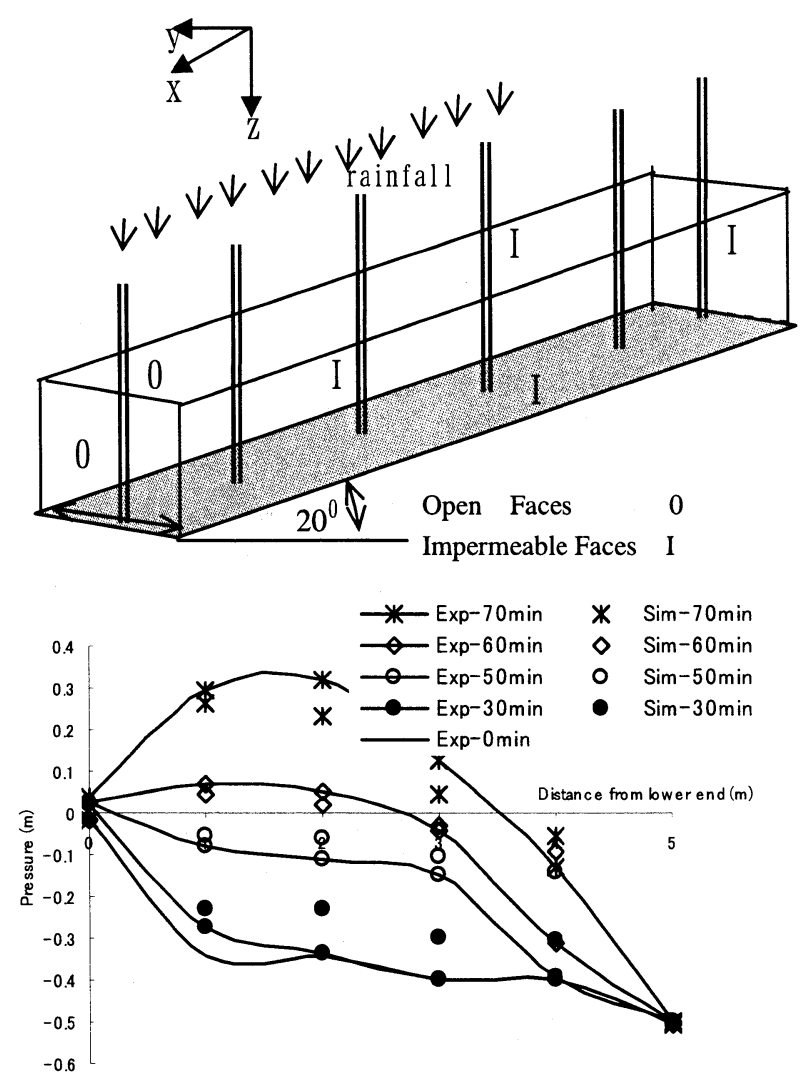

Fig.2 Set up of experimental flume and tensiometers (top) and Experimental and simulated soil moisture profile (bottom)

and the resistance shear stress, $\tau_{B L}$, at the interface of B/C-layer, are expressed respectively by

$$
\tau_{B}=g \sin \alpha \cos \alpha\left[\begin{array}{l}
D_{B}\left(1-\lambda_{B}\right) \sigma_{B}+ \\
\rho\left\{\int_{D_{A}}^{D_{A}+D_{B}-H_{B}} \theta d z+H_{B} \lambda_{B}+H_{s}\right\}
\end{array}\right]
$$

$\tau_{B L}=\left[\begin{array}{l}\tau_{A} \tan \phi_{B} / \tan \alpha+ \\ +g \cos ^{2} \alpha\left\{\begin{array}{l}\left(D_{B}-H_{B}\right)\left(1-\lambda_{B}\right) \sigma_{B} \\ +\rho \int_{D_{A}+D_{B}-H_{B}}^{D_{D_{A}}} \theta d z \\ +H_{B}\left(1-\lambda_{B}\right)\left(\sigma_{B}-\rho\right)\end{array}\right]\end{array}\right\} \tan \phi_{B}+c_{B}(8)$

where, $D$ and $H$ are thickness and seepage flow depth on soil layers and $H_{s}$ is surface flow depth.

Similarly $\lambda, \sigma, \rho, \phi$ and $c$ are porosity of a soil layer, density of a sediment particle, density of water, angle of repose and cohesion respectively. $g$ is acceleration due to gravity. Subscripts A or B denotes a value in A layer or B layer. When, $H_{A} \geq D_{A}$, it is set that $H_{A}=D_{A}$ and when $H_{B} \geq D$, the following equation is used instead of Eq.(5).

$$
\begin{aligned}
& \tau_{B L}=\left(\tau_{A L}-c_{A}\right) \tan \phi_{B} / \tan \phi_{A} \\
& +g \cos ^{2} \alpha D_{B}\left(1-\lambda_{B}\right)\left(\sigma_{B}-\rho\right) \tan \phi_{B}+c_{B}
\end{aligned}
$$



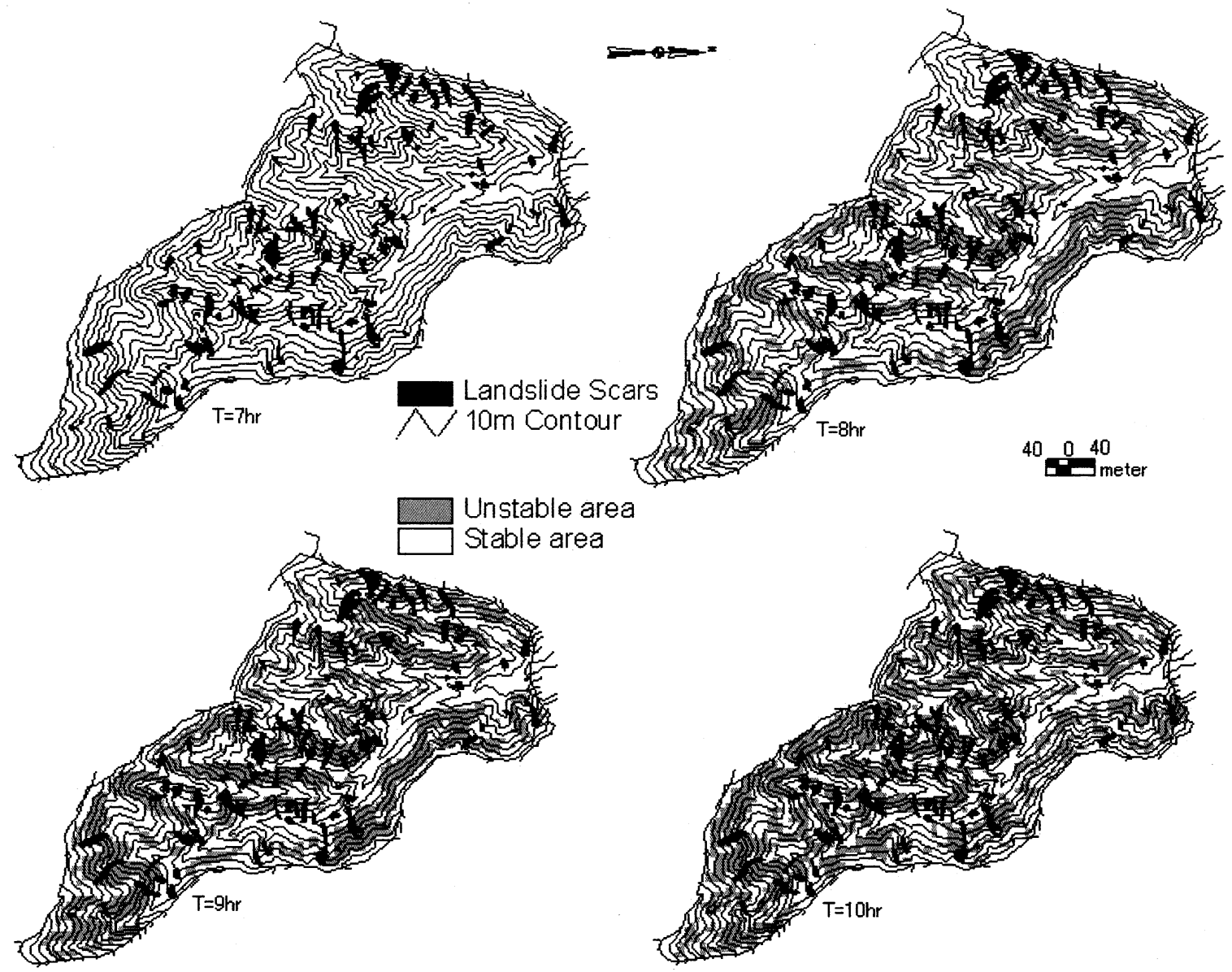

Fig3. Historical landslide scars and stability map of an area at the end of 7, 8, 9 and 10 hours of the rainfall event

The safety factor $S F_{A}$ and $S F_{B}$ for A and $\mathrm{B}$ layer respectively are function of time dependent parameters $H_{A}, H_{B}$ and $H_{s}$. SF for each time step, on each layer, is calculated using following equation;

$$
\begin{aligned}
& S F_{A}=\tau_{A L} / \tau_{A} \\
& S F_{B}=\tau_{B L} / \tau_{B}
\end{aligned}
$$

\section{NUMERICAL SIMULATION AND EXPERIMENTAL VERIFICATION OF SOIL MOISTURE MOVEMENT}

Algorithms developed by Paceman/Rachford and Douglas/Gunn on Alternate Direction Implicit (ADI) are widely employed for diffusion equations. In this study we use the Douglas-Gunn Approach because the Paceman/Rachford approach has second order accuracy and is unconditionally stable only for the $2 \mathrm{D}$ problems. Douglas/Gunn approach is unconditionally stable in $3 \mathrm{D}^{4)}$.

The pore pressure simulation capacity of the model was verified with the flume experiment data $^{5)}$. The experimental data of change in pressure of initially unsaturated soil in $5 \mathrm{~m}$ long flume sloped at $20^{\circ}$ with average rainfall of $82 \mathrm{~mm} / \mathrm{hr}$ was used for the purpose. The result of simulated and experimental pore water pressure is shown in Fig. 2 .

\section{APPLICATION OF THE MODEL}

A short-duration and high-intensity rainfall event had impacted the Takora basin, on 26th September 1973. The length of the event was $10 \mathrm{hr}$ with the total rainfall amount of $282.25 \mathrm{~mm}$. Within 7th, 8th and 9th hour of event almost 218 $\mathrm{mm}$ of rain fell within the study area, triggering many landslides. Air photos were taken in the year 1975 for locating the shallow landslides distribution in the area. No other major rainfall events appear to have occurred within the time window covered by the time of that major rainfall and time of taking air photo. Hence, all the landslide scars seen in the map were assumed to be caused by heavy rainfall of 1973 . 

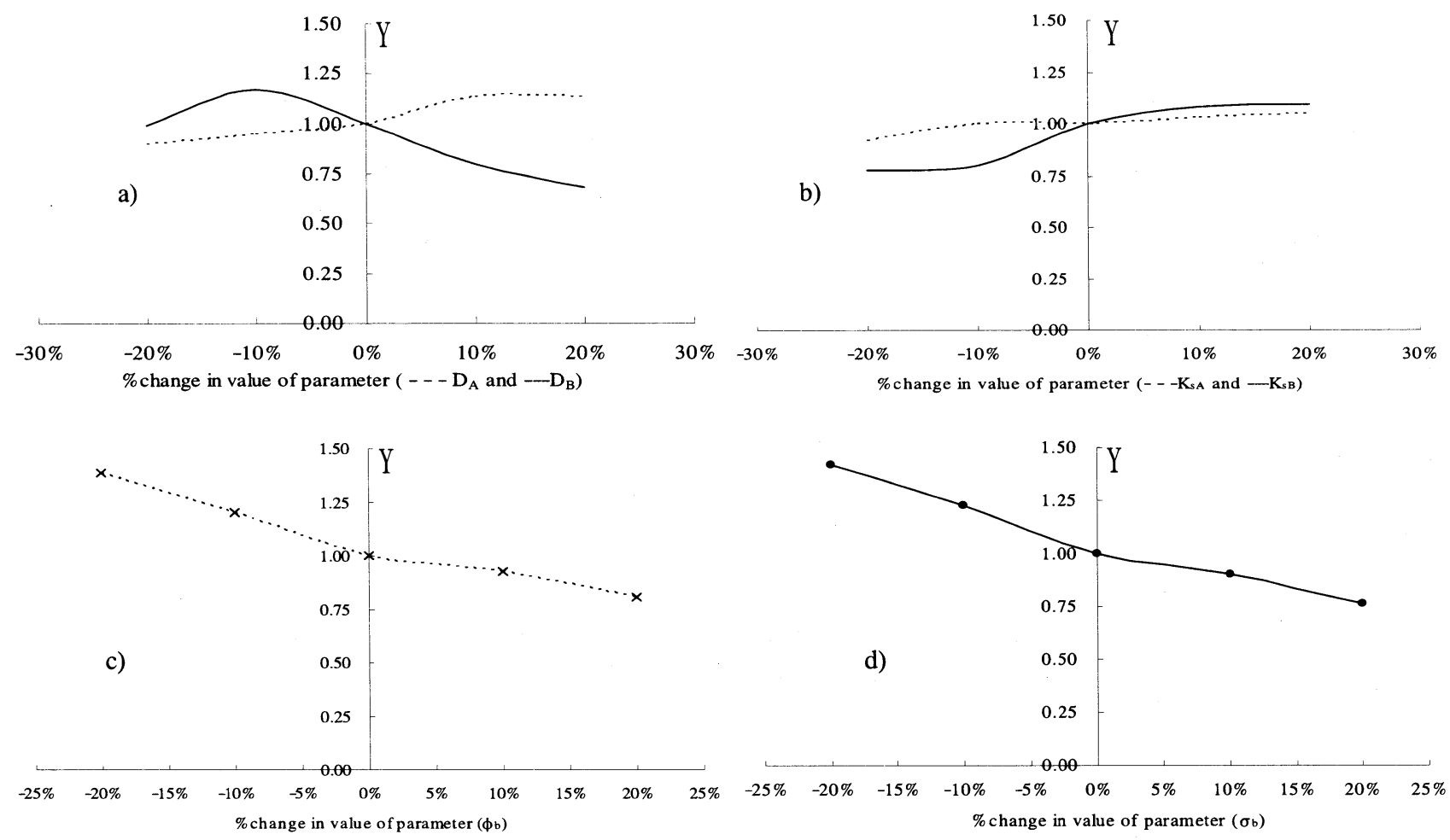

Fig.4 Sensitivity of parameters ( $\mathrm{Y}$ axis is the ratio of unstable are after changed value of parameter and unstable area with original parameter value)

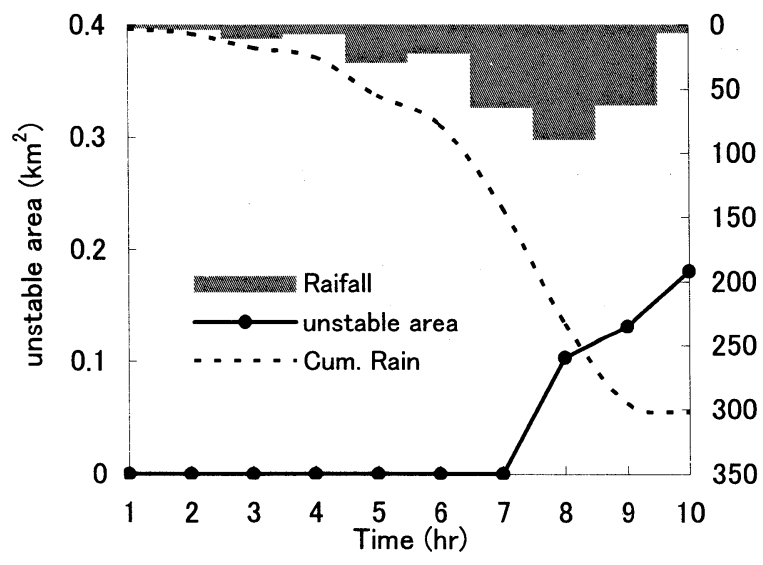

Fig.5 Rainfall Event on 1973/10/26 and calculated unstable area

The prepared model was applied on $0.3812 \mathrm{~km}^{2}$ Takora basin, for determination of the temporal and spatial distribution of the landslides due to that rainfall. The DEM with grid size of $10 \mathrm{~m}$ was created from the topographic map available, after digitizing the contours.

The model parameters were used from the literatures of the previous landslide study of the area ${ }^{3)}$. Saturated hydraulic conductivity is taken as $72 \mathrm{~mm} / \mathrm{hr}, 36 \mathrm{~mm} / \mathrm{hr}$ and $7.2 \mathrm{~mm} / \mathrm{hr}$ for layer A, B and $\mathrm{C}$ respectively. Similarly, soil depth as 0.3 and $0.52 \mathrm{~m}$, density $2.4 \mathrm{~g} / \mathrm{cm}^{3}$ and $2.6 \mathrm{~g} / \mathrm{cm}^{3}$ were taken respectively for layer $A$ and $B$. Cohesion of soil is neglected ${ }^{2}$. Static pressure distribution was assumed as initial condition before rainfall with zero matric potential is assumed at bottom of B-layer and decrease upward to be in static equilibrium. Stability is calculated for the failure of B layer since; the historical data shows that depth of the landslides in basin was $0.82 \mathrm{~m}^{2)}$.

\section{RESULT AND DISCUSSION}

The result of 3D numerical simulation and experimental data of the transient pore pressure change (Fig.3) encourage extending the model for landslide prediction. Uniform soil moisture distribution in vertical direction was assumed which might be a cause of the slight variation of numerical and experimental result in initial 30 minutes. The result thereafter is close to the experimental data.

The landslide analysis model was then applied to Takura Basin to calculate the safety factor of each grid in every time step. It was assumed that if the Safety Factor reduces than 1 than such grid will fail. Fig.3 shows the stability of the area after 7, 8, 9 and 10 hour of rainfall. Fig.5 shows the rainfall event of 1973/10/26. High intensity rainfall starts from the end of sixth hour and the landslides starts from the end of seventh hour till the end of the event. The time lag is the time required for rain water to infiltrate and generate sufficient pore water pressure for the failure. In 7th - 8th hour, rate of slope failure is very high compared to that of 8 th -9 th and 9 th 10th hour.

After the end of 10 hour rainfall event $43 \%$ of the area was classified as unstable $(\mathrm{FS}<1)$, and $64 \%$ of the actual landslides were correctly localized within this area. This means the landslide 
model correctly predict the landslides with $64 \%$ accuracy.

In the model all the parameters except the topography and the rainfall pattern are kept uniform. Other parameters such as soil friction angle, soil density, permeability of soil layers, depth of layers etc are also important factors that may change the landslide propensity. Hence, sensitivity analysis of some parameters was done so that their importance in future generalization of model can be treated aptly.

Depth and saturated hydraulic conductivity of soil layer A and B have significant influence on stability of the soil domain. The soil friction angle and specific density are other parameters that plays vital role in determination of the stability. To study the sensitivity of stability of area to variation on these parameters, each parameter was varied by $\pm 20 \%$, so that correct influence of each parameter can be recognized. Sensitivity analysis is carried on to evaluate the failure of the layer B.

Fig.4a shows how soil depth of upper layer A influences the stability of layer B. Increase in depth of A layer reduces stability of A and B both layers. This happens as the hydraulic conductivity of layer A increases, there is chance of rapid increase in pore water pressure due to higher conductivity of A layer. In the other hand increase in the depth of layer B increases the stability because this increases the resisting shear stress of the soil after increment in depth. Increase in depth of B layer also increases the time required for sufficient pore water pressure development because the moisture have to move greater distance to reach the interface of $\mathrm{B} / \mathrm{C}$ layer. The result shows the depth of layer $B$ is of more vital than layer A for stability calculation.

Fig. $4 \mathrm{~b}$ indicates that increase in hydraulic conductivity of A or B layer both will reduce the stability of area. But the hydraulic conductivity of Layer A is less sensitive than that of layer B.

Fig.4c and d show that increase in soil friction angle and specific density of soil both reduce the unstable area. Influences of these two parameters seem to be vital in dictating the stability of area. This shows the importance of these spatially variable parameters for better model performance.

\section{CONCLUSION}

For the prediction of the shallow landslide, mechanistic type of model capable to reproduce the correct pore-pressure in response to high-intensity rainfall is essential. The result shows that using the physics based mechanistic model it is possible to predict the location and the timing of the landslides in conjunction with the given rainfall.

The result of the numerical simulation and its experimental verification indicates that the model can appropriately calculate the transient pore pressure development due to the high intensity and short duration rainfall.

The landslide model was used to simulate landslides triggered by a rainfall event in Takora Basin. The event was one of the high intensity and short duration rainfalls in the hydrological history of the basin. The model was able to predict the landslides with $64 \%$ accuracy on the basin.

As most of the landslide affecting parameters as spatial distribution of rainfall, spatial variability of soil properties as cohesion, soil angle of friction and the landuse practice on the area all were taken constant here which are actually variable in the real world. If such data can be used better result could be expected. The sensitivity analysis also indicates that the soil parameters have great influence on the stability of the soil domain. The result of infiltration modeling and landslide modeling both proves the applicability of the model and encourage for the future extension incorporating more landslide triggering factors explicitly.

\section{ACKNOWLEDGEMENTS}

Authors like to acknowledge Dr. Diazo Tsutsumi for providing experimental data.

\section{REFERENCES}

1) Casadei, M., Dietrich, W. E. and Miller, N. L.: Testing a model for Predicting the Timing and Location of Shallow Landslides initiation in Soil-Mantled Landscapes, Earth Surface Processes and Landforms, pp.925-950, 2003.

2) Takahasi, T. and Nakagawa, H.: Prediction of Occurrence and Volume of Surface Landslides, Proceeding of the $30^{\text {th }}$ Japanese Conference on Hydraulics, JSCE, pp.199-204 (in Japanese).

3) Robert Leconte and Francois P. Brissette: Soil Moisture Profile for Two-Layered Soil Based on Sharp Wetting Front Approach, Journal of Hydrologic Engineering, ASCE, Vol.6, No.2, pp.141-149,2001.

4) Ting-Yuan Wang and Charlie Chung-Ping Chen: $3-D$ Thermal-ADI: A Linear-Time Chip Level Transient Thermal Simulator, IEEE Transactions on Computer-Aided Design of Integrated Circuits and Systems, Vol.21, No.12, pp.1434-1445, 2002.

5) Diazo Tsutsumi, Roy C. Sidle, Masaharu Fujita and Takahasi Mizuyama: Numerical Experiments to assess the influence of pipe on slope stability, Annual Journal of Hydraulic Engineering, , JSCE, Vol.48, 2004

6) Carlso Alexandre Bastos de Vasconcellos and Jose Carlos Cesar Amorim: Numerical Simulation of Unsaturated Flow in Porous Media Using a Mass-Conservative Model, $16^{\text {th }}$ Brazilian Congress of Mechanical Engineering, 2001.

7) Richard M. Iverson: Landslide Triggering by Rain Infiltration, Water Resources Research, Vol.36, No.7, pp.1897-1910, 2000.

(Received September 30, 2004) 